\title{
Judy Lupart: A Tribute to a Woman Who Led the Way
}

\author{
Nancy L. Hutchinson \\ Queen's University
}

I am honoured to offer a brief tribute to Judy Lupart, a trail blazer in inclusive education in Canada. I look back over the past two decades to highlight how Judy's efforts have contributed to our current accomplishments in inclusion and have challenged us to ensure education for all.

In 1992, Judy Lupart foreshadowed the critical issues of the next 10 years when she wrote of the "complex and multifaceted" school reforms underway as special education gave way to "a unified system of education." In her introduction to a special issue of this journal, she highlighted three dilemmas that characterized the magnitude of these reforms. The first dilemma was the need for change so that provincial education policies enhanced inclusion without compromising quality. The second dilemma focused on researchers and practitioners using the existing special education knowledge base to inform best practice in inclusive contexts until we developed comparable knowledge about inclusive classrooms. And, thirdly, she acknowledged the central role of classroom teachers in this momentous change.

A decade later, in her 2002 opus "Canadian Schools in Transition" written with Charles Webber, Judy challenged us again to respond to the complexities and contradictions inherent in the transition toward inclusive schools. She acknowledged the disillusionment of many in the 1990s with the ability of the public school system to meet so many diverse needs. Whereas others might have seen these obstacles as overwhelming, Judy suggested ways out of these potential impasses. She issued a challenge, which has been heeded by researchers and practitioners, when she wrote that "it is incumbent upon both parents and educators to collaborate on restructuring plans." She urged researchers and policy makers to listen to parents and to provide constructive support for the central role of classroom teachers in educating and socializing all students. Change, she acknowledged, was not easy while she led us by example - editing a journal that fostered important conversations and celebrated embracing these challenges in a uniquely Canadian way.

In 2012, a group of Canadian researchers reported on the experiences of three parents as their children with developmental disabilities and delays transitioned into kindergarten in Ontario schools (Villeneuve et al., in press). In all three cases, the parents expected their children to be fully participating members of inclusive classrooms, just as Judy had anticipated and fought for throughout her career. The parents of Abby, who has Down syndrome, were advocates for Abby and for all children with Down syndrome and Judy would enjoy hearing them describe 
their successful efforts to ensure that Abby learned the same things as her classmates. Brady, who has autism and severe hearing loss, experienced what his guardian fervently lobbied for: that he "stay in the classroom with his peers as much as possible," while receiving some specialized services outside the classroom to enhance his communication with peers and teachers. Tristan-who had experienced significant health issues, long hospitalizations, and delayed development in all areas-thrived in a small kindergarten classroom while his mother's perspective on inclusion grew from focusing on his presence with his peers to his learning with his peers. And, as Judy foresaw, his teacher and parent became "co-advocates" for his inclusion "as a regular member, just like everyone else, in the classroom."

As we honour one of the trail blazers in inclusive education in Canada, let us celebrate all that has been accomplished while using this occasion to re-commit to the inclusion of all in $\mathrm{Ca}$ nadian schools, communities, and the wider society. Thanks to you, Judy, for leading the way. We will continue to chase challenge and embrace dilemmas, as you have done throughout your career.

\section{References}

Villeneuve, M., Chatenoud, C., Hutchinson, N. L., Minnes, P., Perry, A., Dionne, C.,...Weiss, J. (in press). The experience of parents as their children with developmental disabilities transition from early intervention to kindergarten. Canadian Journal of Education.

\section{Author's Note}

Correspondence concerning this commentary should be addressed to Nancy Hutchinson, Faculty of Education, Queen's University, 511 Union Street, Kingston, ON, K7M 5R7.

Email: nancy.hutchinson@queensu.ca 